\title{
Total wrist arthrodesis for septic wrist arthritis and loss of the bony carpus following percutaneous pinning of the fifth carpometacarpal joint: a case report
}

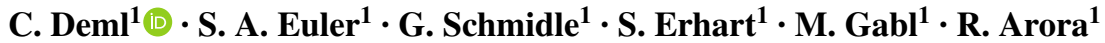

Received: 3 February 2017 / Published online: 1 March 2017

(C) The Author(s) 2017. This article is published with open access at Springerlink.com

\begin{abstract}
We report on a patient who developed septic wrist arthritis with destruction of the entire carpus due to osteomyelitis following percutaneous pinning of a fifth metacarpal base fracture. Arthrodesis was performed using a $6 \mathrm{~cm}$ vascularized iliac bone graft. This case report may sharpen the surgeon's awareness of risks in orthopedic surgeries, even though the procedure seems to be rather simple and the patient is young and seems to be healthy.
\end{abstract}

Keywords Septic arthritis $\cdot$ Wrist $\cdot$ Arthrodesis $\cdot$ Wristfusion

\section{Case report}

Septic wrist arthritis (SWA) is defined as an infection of involving one or all of the radio-carpal, mid-carpal, distal radio-ulnar and carpo-metacarpal joints. In severe cases, the infection can extend into the carpal tunnel and the surrounding subcutaneous tissues [1]. Several articles are published, proposing potential pathways for the diagnosis and treatment of SWA [2]. We present a case of an end stage SWA with complete loss of the bony carpus following percutaneous pinning of the fifth carpo-metacarpal (CMC) joint, resulting in a total wrist arthrodesis. The patient was asked for submission and publication of his data and agreed.

A 30-year-old man presented in a district hospital after a fall on ice. He injured the base of the fifth metacarpal bone

\section{$\triangle$ C. Deml}

Christian.Deml@tirol-kliniken.at

1 Department of Trauma Surgery, Medical University Innsbruck, Anichstrasse 35, 6020 Innsbruck, Austria and had a closed comminuted fracture. The CMC was not dislocated and the axis of the metacarpal bone was displaced palmary, $10^{\circ}-15^{\circ}$ in loss of extension. He suffers diabetes type 2 . The orthopedic surgeon on call decided to surgically treat the injury using percutaneous pin fixation on the next day (Fig. 1). After the second postop X-ray at day 17 , the patient developed some pain. Because of a fluctuant swelling of the hand with erythema and signs of pin infection, the pin was removed without any surgical revision. The patient was then sent home with oral antibiotics (Cefuroxim) as a "standard treatment" and scheduled for a follow-up examination. 4 weeks following pin-removal, radiographs showed a continuous infection with osteomyelitis and bony erosions of the entire carpus, including the metacarpals and the distal forearm. Finally, the patient was transferred to our University hospital. The MRI showed osteomyelitis in all carpal bones, the bases of all metacarpal bones and the distal areas of radius and ulna (Fig. 2).

Initial blood tests revealed a glucose concentration of $301 \mathrm{mg} / \mathrm{dl}$, an $\mathrm{HbA}_{1 \mathrm{C}}$ of $10 \%$ and a CRP of $2.61 \mathrm{mg} / \mathrm{dl}$. However, the white blood cell count (WBC) was found normal $\left[8.3(4.5-12.5) \times 10^{9} / 1\right]$.

Accordingly, the former pinhole and a fistula at the ulnometacarpal area were excised in a second revision surgery. A central approach was chosen, starting between the second and third metacarpal bones, continuing proximally towards the Lister tubercle of the radius. A second fistula was found in the middle dorsum of the wrist. The subcutaneous and peritendinous tissue was fully indurated, and diffuse chambers of pus were found. The dorsal joint capsule was found to appear completely infiltrated and eroded by the infection. The wrist exhibited gross instability due to destruction of the intrinsic ligaments. Again, diffuse accumulations of pus were found in these areas. The cartilage of the carpal bones was partly destroyed, and the bony structure appeared soft 
Fig. 1 a Preoperative CT-scan revealing a metacarpal five fracture. b Postoperative p/a radiograph following pin fixation
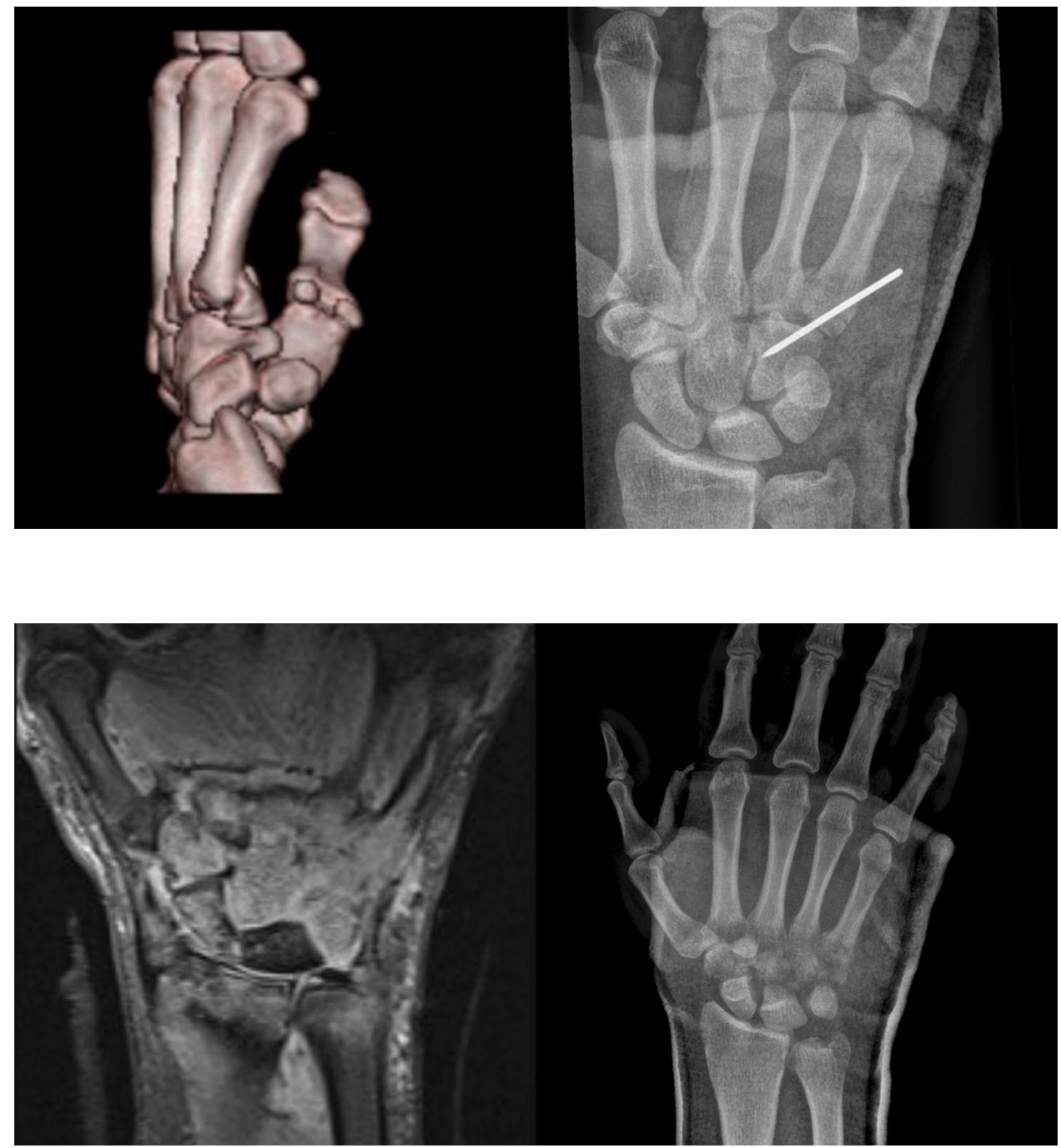

Fig. 2 a MRI and b p/a radiograph at initial presentation in our department. Vast erosions of the wrist bones due to osteomyelitis. The MRI shows septic arthritis beginning in the bases of the metacarpal bones continuing proximally to the distal parts of radius and ulna and weak. All carpal bones except half of the trapezium, as well as the bases of the second to fifth metacarpal bones and the surfaces of radius and ulna had to be resected. Debridement and synovectomy of the flexor tendons were performed and the median nerve was inspected through the dorsal approach as well (Fig. 3). After meticulous irrigation and installation of an external fixator, the defect and the wounds were covered using a VAC System. Postoperatively, a diabetic specialist followed the patient daily during his stay in the hospital to maintain low blood sugar levels. The bacteriologic tests of the tissue samples collected at multiple different areas during surgery showed multi-resistant Staphylococcus aureus (ORSA) and Staphylococcus epidermidis. Antibiotic treatment using Linezolid and Fosfomycin was started immediately, according to the recommendations of the consulted University department of medical microbiology. 18 days after the initial revision surgery, followed by four revision procedures, the VAC System was finally removed, a Palacos cement spacer, saturated with
Vancomyzin, was placed into the defect and the wound was closed. At this time, all collected tissue samples of the most recent revision surgery were found to be sterile and the patient was dismissed with continuous oral antibiotic therapy (Linezolid $1200 \mathrm{mg} / \mathrm{d}$ ). 14 days later (32 days after initial revision), the definitive fusion of the wrist was performed, implanting a vascularized iliac bone auto graft $(6 \times 3 \mathrm{~cm})$ connecting to the radial artery. Necrotic wound margins of $3 \times 0.5 \mathrm{~cm}$ necessitated a visor flap from radial and split skin grafting. Bony healing was achieved after 3 months, and acceptable mobility of the thumb and index finger were accomplished after 12 months (Fig. 4).

\section{Discussion}

We present a severe case of SWA, leading to a resection of the complete bony carpus and a total wrist arthrodesis following pin fixation of the CMC joint. 


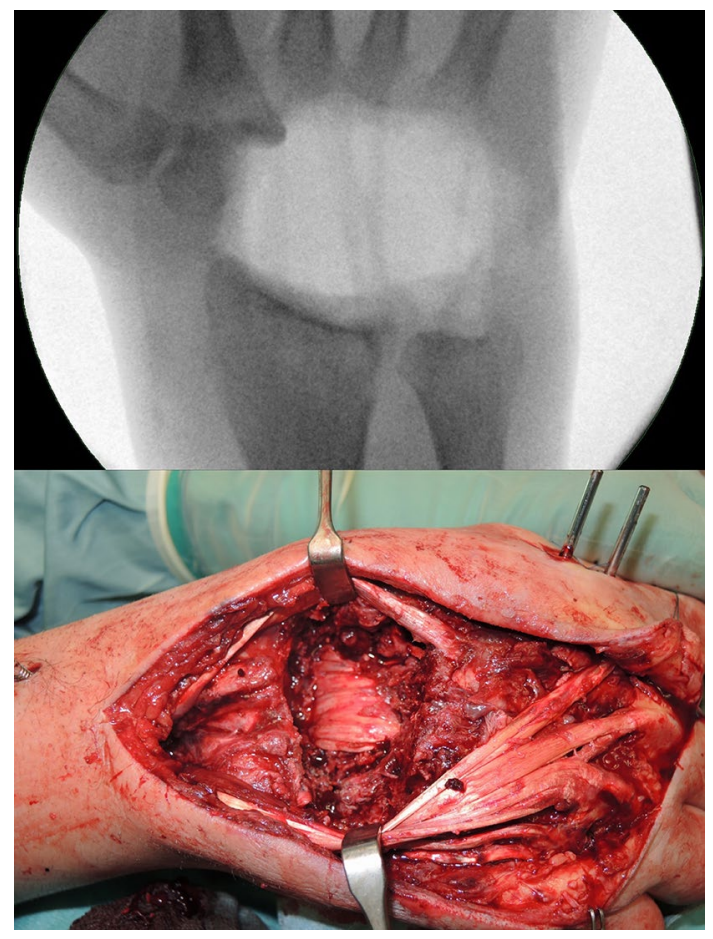

Fig. 3 a Intraoperative fluoroscopy showing the complete carpal resection. b Surgical situs following carpectomy and meticulous soft tissue debridement

Diagnosis of SWA may be difficult, even for experienced physicians. The incidence of confirmed and likely septic arthritis in Western Europe is 4-10 per 100,000 patients per year [3, 10]. Risk factors for the development of SWA include rheumatoid arthritis, multiple drug abuse (psychotropic drugs), chronic alcohol abuse, previous intraarticular corticosteroid injections, cutaneous ulcers and insulin-dependent diabetes, as well as a low socio-economic status $[5,8,11]$. However, SWA may also occur following a surgical intervention. Our patient suffered severe insulin-dependent diabetes. There is hardly any evidence about the type and timing of the antibiotic treatment and clear guidelines are still missing [14]. The gold standard for the treatment of SWA is the initial needle aspiration. Examination of aspirated sample should include gram stain, culture, WBC and differential and microscopy for crystals. Finding gout or pseudo gout crystals does not exclude additional infection. As a second step, the surgical intervention as well as revision surgeries if needed are recommended $[1,6,7]$. Additional antibiotic treatments should be initiated according to the generated antibiogram using the collected tissue samples of the index surgical procedure. Studies showed that the most common bacteria detected were Staphylococcus aureus [9, 15]. The average duration of antibiotic treatment has been explained diversely in literature. The authors describe treatment periods between 5 and 180 days $[7,15]$. There is hardly any evidence about the sequence, combination, or the superiority of primary closed needle aspiration and surgical aspiration with or without arthroscopy. In early stages, arthroscopic irrigation has shown likely better outcomes than the open revision with irrigation [12]. However, due to the severe grade of osteomyelitis within the carpal bones, this was not an option within our patient. Agreement exists that the key of treatment should include early removal of any
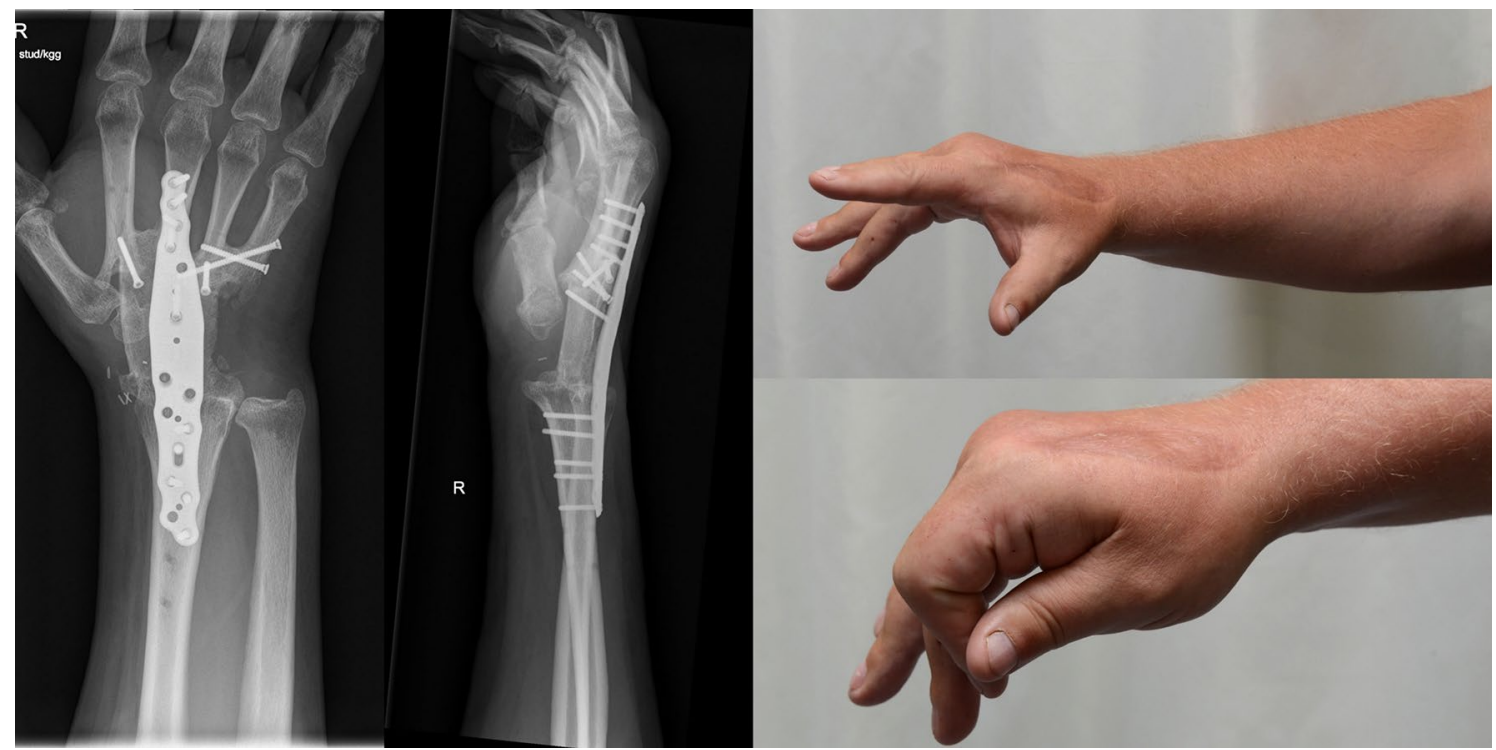

Fig. 4 a 12 months follow-up radiographs showing bony union of the arthrodesis. Acceptable and stable alignment of the first digital ray without any further proximalization, resulting in a limited but satisfactory range of motion for the patient with the ability to perform a pinch grip (b) 
infected material in combination with an individual and selective antibiotic treatment [2].

Negative WBC and negative or only slightly elevated CRP count have been described by other authors in comparable cases of septic arthritis before [9]. This may be a potential reason for the underestimation of the early stage pathology of a septic arthritis. Therefore, it seems to be important to precisely survey all anamnestic information and to closely consider possible risk factors. The initial blood glucose level in our patient was over $300 \mathrm{mg} /$ $\mathrm{dl}$ and the $\mathrm{HbA}_{1 \mathrm{C}}$ test of $10 \%$ revealed a poorly regulated insulin-dependent diabetes. In combination with postoperative clinical signs of infection, including erythema and swelling, the treating doctor must be sensitized and aware of an infection. Care should be taken in cases with slightly spotted decalcification on the radiographs in combination with limited range of motion and pain, not to misdiagnose a chronic regional pain syndrome. Additional investigations like ultrasound or MRI might be helpful to further elucidate potential early stages of infection. In our case, the radiographs of the infected hand with osteomyelitis and erosions of the entire carpus were obvious signs of the ongoing infection.

The clinical outcome after SWA is poor and disappointing in the majority of the cases. In up to $73 \%$ of the cases, SWA results in a partially destroyed joint or may even result in amputation $[4,13,15]$.

This case report may sharpen the surgeon's awareness of risks in orthopedic surgeries, even though the procedure seems to be rather simple and the patient is young and healthy.

Acknowledgements Open access funding provided by University of Innsbruck and Medical University of Innsbruck.

\section{Compliance with ethical standards}

Disclosure This article is in compliance with ethical standards.

Conflict of interest All named authors hereby declare that they have no conflicts of interest to disclose.

Funding This work received no specific grant from any funding agency in the public, commercial, or not-for-profit sectors.

Ethical approval This article does not contain any studies with human participants or animals performed by any of the authors. This article is a case report.

Informed consent Informed consent was obtained from the reported patient to present his medical data.

Open Access This article is distributed under the terms of the Creative Commons Attribution 4.0 International License (http:// creativecommons.org/licenses/by/4.0/), which permits unrestricted use, distribution, and reproduction in any medium, provided you give appropriate credit to the original author(s) and the source, provide a link to the Creative Commons license, and indicate if changes were made.

\section{References}

1. Birman MV, Strauch RJ (2011) Management of the septic wrist. Am J Hand Surg 36(2):324-326 (quiz 327)

2. Coakley G, Mathews C, Field M et al (2006) BSR \& BHPR, BOA, RCGP and BSAC guidelines for management of the hot swollen joint in adults. Rheumatology (Oxford) 45(8):1039-1041

3. Kaandorp CJ, Dinant HJ, van de Laar MA, Moens HJ, Prins AP, Dijkmans BA (1997) Incidence and sources of native and prosthetic joint infection: a community based prospective survey. Ann Rheum Dis 56(8):470-475

4. Kaandorp CJ, Krijnen P, Moens HJ, Habbema JD, van Schaardenburg D (1997) The outcome of bacterial arthritis: a prospective community-based study. Arthritis Rheum 40(5):884-892

5. Lauing KL, Roper PM, Nauer RK, Callaci JJ (2012) Acute alcohol exposure impairs fracture healing and deregulates betacatenin signaling in the fracture callus. Alcohol Clin Exp Res 36(12):2095-2103

6. Low S, Spies CK, Unglaub F, van Schoonhoven J, Prommersberger KJ, Muhldorfer-Fodor M (2017) Preventable repeat wrist arthroscopies: analysis of the indications for 133 cases. J Wrist Surg 6(1):33-38

7. Mathews CJ, Weston VC, Jones A, Field M, Coakley G (2010) Bacterial septic arthritis in adults. The Lancet 375(9717):846-855

8. Mathog RH, Toma V, Clayman L, Wolf S (2000) Nonunion of the mandible: an analysis of contributing factors. J Oral Maxillofac Surg 58(7):746-752 (discussion 752-743)

9. Meier R, Lanz U (2007) Septic arthritis of the wrist. Handchirurgie, Mikrochirurgie, plastische Chirurgie: Organ der Deutschsprachigen Arbeitsgemeinschaft fur Handchirurgie : Organ der Deutschsprachigen Arbeitsgemeinschaft fur Mikrochirurgie der Peripheren Nerven und Gefasse 39(2):112-117

10. Morgan DS, Fisher D, Merianos A, Currie BJ (1996) An 18 year clinical review of septic arthritis from tropical Australia. Epidemiol Infect 117(3):423-428

11. Ovaska MT, Makinen TJ, Madanat R, Vahlberg T, Hirvensalo E, Lindahl J (2013) Predictors of poor outcomes following deep infection after internal fixation of ankle fractures. Injury 44(7):1002-1006

12. Sammer DM, Shin AY (2009) Comparison of arthroscopic and open treatment of septic arthritis of the wrist. JBJS Am 91(6):1387-1393

13. Shirtliff ME, Mader JT (2002) Acute septic arthritis. Clin Microbiol Rev 15(4):527-544

14. Stengel D, Bauwens K, Sehouli J, Ekkernkamp A, Porzsolt F (2001) Systematic review and meta-analysis of antibiotic therapy for bone and joint infections. Lancet Infect Dis 1(3):175-188

15. Yap RT, Tay SC (2015) Wrist septic arthritis: an 11 year review. Hand Surg 20(3):391-395 